This document is the unedited Author's version of a Submitted Work that was subsequently accepted for publication in Organic Lettters, copyright (C) American Chemical Society after peer review. To access the final edited and published work see http://pubs.acs.org/doi/abs/10.1021/acs.orglett.5b01317 


\title{
One-Pot Hydrogen Peroxide and Hydrohalic acid Induced Ring Closure and Selective Aromatic Halogenation to give New Ring- Fused Benzimidazoles
}

\author{
Michael Gurry, Martin Sweeney, Patrick McArdle, and Fawaz Aldabbagh* \\ School of Chemistry, National University of Ireland Galway, University Road, Galway, Ireland \\ Supporting Information
}

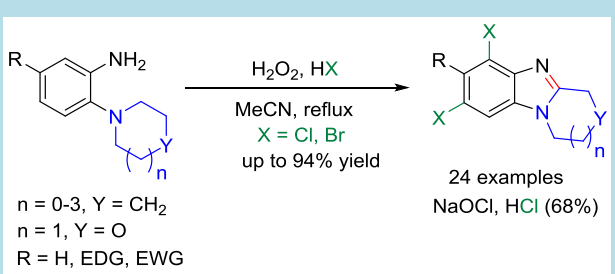

ABSTRACT: A new series of selectively dichlorinated and dibrominated five to eight-membered ring [1,2-a] fused benzimidazoles and $[1,4]$ oxazino[4,3-a]benzimidazoles are synthesized in mostly high yields of $>80 \%$ using the reaction of hydrogen peroxide and hydrohalic acid with commercially available $o$-cyclic amine substituted anilines. Domestic bleach with $\mathrm{HCl}$ is also capable of a one-pot ring-closure and chlorination.

The combination of hydrogen peroxide and hydrohalic acid ( $\mathrm{HX}$, where $\mathrm{X}=\mathrm{Cl}, \mathrm{Br}$ ) is a source of electrophilic chlorine and bromine that can be used for facile aromatic halogenations. ${ }^{1-4}$ Moreover $\mathrm{H}_{2} \mathrm{O}_{2}$ and $\mathrm{HCl}$ has been reported to give 4,6dichlorination of 5-hydroxybenzimidazole. ${ }^{5} \quad 1$ Chlorobenzimidazole can be formed by reacting benzimidazole with sodium hypochlorite $(\mathrm{NaOCl})$ in $\mathrm{CCl}_{4} \cdot{ }^{6}$ The intermediate of the reaction between $\mathrm{H}_{2} \mathrm{O}_{2}$ and $\mathrm{HCl}$ is hypochlorous acid $(\mathrm{HOCl})$, which is commonly used to disinfect water, and its salt is the active ingredient in domestic bleaches. The oxidizing solution is very cheap, low in molecular weight, and allows the in situ generation of elemental chlorine and bromine with the by-product being water. Therefore there are significant green and technical advantages to using $\mathrm{H}_{2} \mathrm{O}_{2}-\mathrm{HX}$ in organic synthesis.

More than fifty years ago, it was recognized that a combination of $\mathrm{H}_{2} \mathrm{O}_{2}$ and trifluoroacetic acid could be used to prepare ring-fused benzimidazoles in good yields from $o$-cyclic amine substituted anilines. ${ }^{7}$ The use of o-tert-aminoacetanilides with peroxide (including $\mathrm{H}_{2} \mathrm{O}_{2}{ }^{8}$ and Oxone ${ }^{9}$ ) in formic acid is recognized as a versatile method for preparing ring-fused benzimidazoles and imidazobenzimidazoles. The preparation of 2-aryl substituted benzimidazoles was reported from the condensation of aryl aldehydes with $o$-phenylenediamines in the presence of $\mathrm{H}_{2} \mathrm{O}_{2-}$ $\mathrm{HCl} .{ }^{10}$ Moderate yields of benzimidazoles and ring-fused benzimidazoles with tetrachlorination of the fused benzene part was reported using the reaction of sulfuryl chloride with $o$ aminodialkylanilines. ${ }^{11}$

Halogenated benzimidazoles have anti-cancer, ${ }^{12}, 13$ antiprotozoal, ${ }^{13}$ anti-tuberculosis, ${ }^{14}$ and anti-hepatitis activity, ${ }^{15}$ as well as, dopamine-receptor binding. ${ }^{16}$ In addition to their biological activity, benzimidazoles chlorinated and brominated at specific sites provide promise as valuable synthetic intermediates. Halogenations of heterocycles are generally carried out in subsequent synthetic step(s) and require the use of difficult to handle $\mathrm{Cl}_{2}, \mathrm{Br}_{2}$ or organic reagents prepared from them. The halogenation of the heterocycle is often associated with low selectivity and when organic reagents are used waste by-products are generated. Our objective was thus to accomplish a one-pot reaction that combined the aromatic halogenation capacity of $\mathrm{H}_{2} \mathrm{O}_{2}-\mathrm{HX}$ with the oxidative cyclization of $o$-cyclic amine substituted anilines to form a new series of valuable halogenated ring-fused benzimidazoles. Herein, is reported the first preparation of specifically dichlorinat- ed and dibrominated ring-fused benzimidazoles from commercially available anilines.

Table 1. Optimization of Reaction Conditions

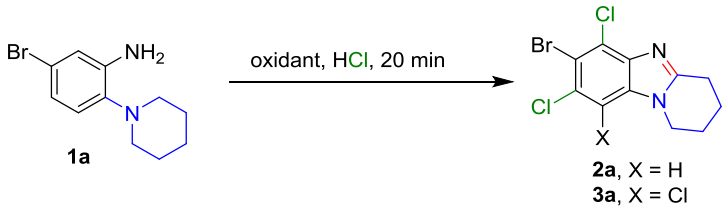

$\begin{array}{ccccc}\text { entry } & \text { oxidant } & \text { solvent } & \text { temp } & \text { yield of 2a (\%) } \\ 1 & \mathrm{H}_{2} \mathrm{O}_{2} & \mathrm{MeCN} & \mathrm{rt} & \text { trace } \\ 2 & \mathrm{H}_{2} \mathrm{O}_{2} & \mathrm{MeCN} & \mathrm{rt}^{a} & 73 \\ 3 & \mathrm{H}_{2} \mathrm{O}_{2} & \mathrm{MeCN} & 50^{\circ} \mathrm{C} & 81 \\ 4 & \mathrm{H}_{2} \mathrm{O}_{2} & \mathrm{MeCN} & \text { reflux } & \mathbf{9 0} \\ 5 & \mathrm{H}_{2} \mathrm{O}_{2} & \mathrm{THF} & \text { reflux } & 83 \\ 6 & \mathrm{H}_{2} \mathrm{O}_{2} & \mathrm{MeOH} & \text { reflux } & 50^{b} \\ 7 & \mathrm{NaOCl}_{8} & \mathrm{MeCN} & \text { reflux } & 68^{c} \\ 8 & \text { household bleach }^{d} & \mathrm{MeCN} & \text { reflux } & 56\end{array}$

Conditions: Aniline 1a $(1.0 \mathrm{mmol})$, oxidant $(10 \mathrm{mmol}), \mathrm{HCl}(12 \mathrm{mmol})$, solvent $(10 \mathrm{~mL}) ;{ }^{a} 4 \mathrm{~h} ;{ }^{b}$ recovery of $\mathbf{1 a}(38 \%)$; ${ }^{c}$ Plus 3a in $15 \%$ yield; ${ }^{d} 20$ $\mathrm{mL}$ of Parazone ${ }^{\circledR}$ thin bleach; ${ }^{e} 1 \mathrm{~h}$

Initially we attempted to establish the one-pot oxidative cyclization and chlorination on 5-bromo-2-piperidin-1-ylaniline 1a in acetonitrile (Table 1). Excess molar amounts of concentrated $\mathrm{HCl}$ relative to $\mathrm{H}_{2} \mathrm{O}_{2}$ were found necessary, and the reaction times were reduced on heating. Monitoring of the reaction by TLC showed the total consumption of aniline 1a within 20 minutes using the optimized conditions (entry 4). 6,8-Dichloroinated pyrido[1,2-a] benzimidazole 2a was isolated in $90 \%$ yield after basic work-up without the requirement for chromatography. This transformation was found to also work in THF and methanol, however yields of $2 \mathbf{a}$ were reduced, and a cleaner reaction occurred in acetonitrile. The sodium salt of hypochlorous acid formed in situ is commonly used in domestic bleaches. We thus decided to replace 
$\mathrm{H}_{2} \mathrm{O}_{2}$ with $\mathrm{NaOCl}$ solution, and found that the desired 2 a could be isolated in $68 \%$ yield, although chromatography was required to separate some trichlorinated benzimidazole $\mathbf{3 a}$ formed in $15 \%$ yield. The reaction was then carried out using a well-known brand of household bleach (containing an unspecified quantity of $\mathrm{NaOCl}$ ) to exclusively give 6,8-dichloro adduct $\mathbf{2 a}$ in $56 \%$ yield with the reduced yield attributed to the purification by chromatography, which separated a number of additives (presumably surfactants and perfumes) in the bleach.

Scheme 1. One-Pot Ring-Fused Benzimidazole Formation with Aromatic Trihalogenation

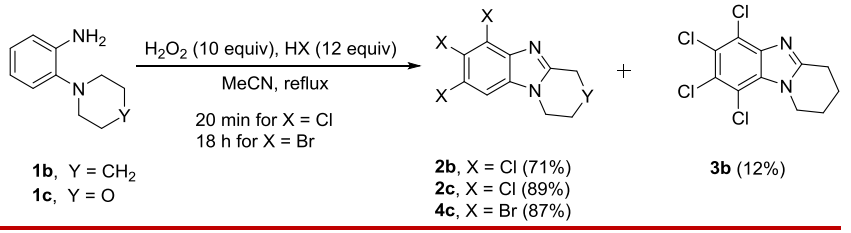

Using the optimized conditions (Table 1, entry 4) the scope and versatility was explored. Firstly we attempted to investigate $o$-cyclic amine substituted anilines devoid of other aromatic substituents (Scheme 1). 2-Piperdin-1-ylaniline (1b) and 2morpholin-4-ylaniline (1c) gave the respective trichlorinated ringfused benzimidazoles $\mathbf{2 b}$ and $\mathbf{2 c}$ in 71 and $89 \%$ yield. Tetrachlorination product $\mathbf{3 b}$ in $12 \%$ yield was separated by column chromatography from $\mathbf{2 b}$. Replacing $\mathrm{HCl}$ by concentrated $\mathrm{HBr}$ transformed piperidine $\mathbf{1 b}$ into dibrominated pyrido[1,2a] benzimidazole $\mathbf{4 b}$ in $94 \%$ yield (Table 3), although under the same conditions the morpholine analogue was tribrominated to give $\mathbf{4 c}$ in $87 \%$ yield (Scheme 1). Attempts at isolating dibrominated benzimidazole from the reaction of $\mathbf{1 c}$ at shorter reaction times were unsuccessful due to the isolation of mixtures of brominated benzimidazoles, and a clean transformation occurred by increasing the reaction time to 18 hours to give exclusively $\mathbf{4 c}$.

The preparation of selectively dichlorinated ring-fused benzimidazoles from various $o$-cyclic amine substituted anilines containing electron-donating and electron-withdrawing groups proved mostly facile with yields of $72-92 \%$ obtained of ring-fused benzimidazoles (Table 2). The substitution of the chlorine atoms was consistent, and did not vary with the nature of the substituent on the aniline, as confirmed by X-ray crystal structures of adducts $\mathbf{2 d}$ and $2 \mathbf{i}$ (Figure 1). ${ }^{17}$ In some cases chromatography was required to separate small amounts of fully chlorinated benzimidazoles $\mathbf{3 b}$ and $\mathbf{3 h}$, although 5-fluoro-2-piperidin-1-ylaniline (1f) tended to prefer cyclization with monochlorination to give $\mathbf{3 f}$ in $62 \%$ yield with the dichlorinated adduct $\mathbf{2 f}$ given in smaller yield of $27 \%$.

Beginning with the optimized conditions (Table 1, entry 4) and replacing $\mathrm{HCl}$ with $\mathrm{HBr}$, the preparation of dibrominated ring-fused benzimidazoles was investigated (Table 3). In some cases the latter reaction conditions used successfully to yield dichlorinated ring-fused benzimidazoles (Table 2) did not require modification, although significantly longer reaction times were required for resonance activators (NHAc and $\mathrm{OMe}$ ) on the aniline.

Table 2. One-Pot Ring-Fused Benzimidazole Formation with Aromatic Dichlorination
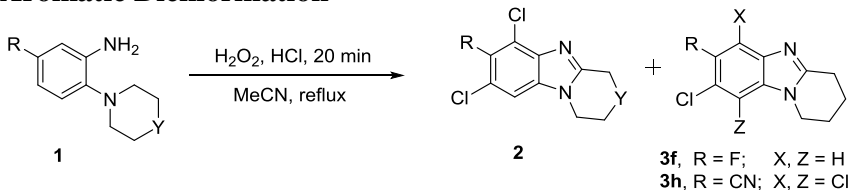

Conditions: Same as in Table 1, entry 4

Figure 1. Crystal Structures of 7,9-dichloro-3,4-dihydro-1 $H$ $[1,4]$ oxazino $[4,3-a]$ benzimidazoles

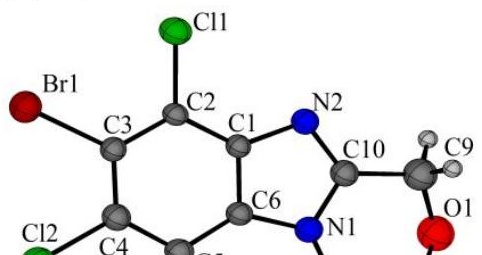

\begin{tabular}{lllll}
$\mathbf{1}$ & $\mathrm{R}$ & $\mathrm{Y}$ & \multicolumn{2}{l}{ yield (\%) } \\
$\mathbf{1 a}$ & $\mathrm{Br}$ & $\mathrm{CH}_{2}$ & $\mathbf{2 a}, \quad 90$ & \\
$\mathbf{1 d}$ & $\mathrm{Br}$ & $\mathrm{O}$ & $\mathbf{2 d}, \quad 92$ & \\
$\mathbf{1 e}$ & $\mathrm{Cl}$ & $\mathrm{CH}_{2}$ & $\mathbf{2 b}, \quad 73+\mathbf{3 b}, \quad 15$ \\
$\mathbf{1 f}$ & $\mathrm{F}$ & $\mathrm{CH}_{2}$ & $\mathbf{2 f}, \quad 27+\mathbf{3 f}, \quad 62$ \\
$\mathbf{1 g}$ & $\mathrm{Me}$ & $\mathrm{CH}_{2}$ & $\mathbf{2 g}, \quad 82$ & \\
$\mathbf{1 h}$ & $\mathrm{CN}$ & $\mathrm{CH}_{2}$ & $\mathbf{2 h}, \quad 79+\mathbf{3 h}, \quad 12$ \\
$\mathbf{1 i}$ & $\mathrm{CF}_{3}$ & $\mathrm{O}$ & $\mathbf{2 i}, \quad 72$ & \\
$\mathbf{1 j}$ & $\mathrm{NHAc}$ & $\mathrm{CH}_{2}$ & $\mathbf{2 j}, \quad 88$ & \\
$\mathbf{1 k}$ & $\mathrm{OMe}$ & $\mathrm{O}$ & $\mathbf{2 k}, \quad 87$ &
\end{tabular}

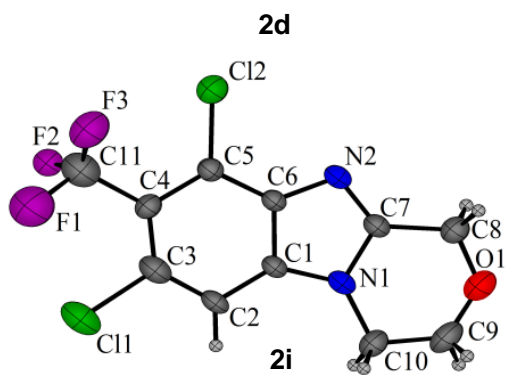

Nevertheless dibrominated ring-fused benzimidazoles were isolated in excellent yield of $74-94 \%$ and without the requirement for chromatography, save for three anilines containing electronwithdrawing groups $\left(\mathrm{F}, \mathrm{CN}, \mathrm{CF}_{3}\right)$. The substitution pattern was the same as for the chlorination, and the positions for the bromination did not vary with the nature of the substituent on the aniline, as confirmed by X-ray crystal structures of dibrominated adducts $\mathbf{4 b}, \mathbf{4 f}$ and $\mathbf{4 m}$ (Figure 2). ${ }^{17}$ Analogous to the results obtained with $\mathrm{H}_{2} \mathrm{O}_{2}-\mathrm{HCl}$, 5-fluoro-2-piperidin-1-ylaniline (1f) gave significant monobromination at pyrido[1,2-a]benzimidazole C-8 with $\mathbf{5 f}$ separated in $31 \%$ yield from the desired dibrominated adduct $\mathbf{4 f}$ isolated in $56 \%$ yield. Surprisingly, the benzonitrile $\mathbf{1 h}$, which gave some polychlorination with $\mathrm{H}_{2} \mathrm{O}_{2}-\mathrm{HCl}$ after only 20 minutes, was found difficult to dibrominate with only the monobromide $\mathbf{5 h}$ isolated in $62 \%$ yield. Further, no brominated benzimidazoles could be cleanly separated from the attempted reaction with 5-(trifluoromethyl)aniline $\mathbf{1 i}$, although the same substrate gave selectively 7,9-dichlorinated [1,4]oxazino[4,3a]benzimidazole $2 \mathrm{i}$ in $72 \%$ yield using $\mathrm{H}_{2} \mathrm{O}_{2}-\mathrm{HCl}$ (Table 2). Thus, it seems that the bromination is more strongly affected by substituents on the aniline than the chlorination with electronwithdrawing substituents making dibromination difficult.

Table 3. One-Pot Ring-Fused Benzimidazole Formation with Aromatic Dibromination

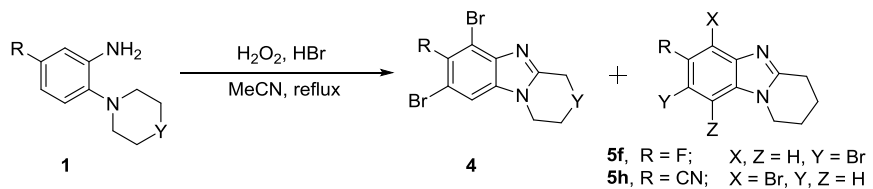




\begin{tabular}{llllll}
$\mathbf{1}$ & $\mathrm{R}$ & $\mathrm{Y}$ & time & \multicolumn{2}{c}{ yield (\%) } \\
$\mathbf{1 a}$ & $\mathrm{Br}$ & $\mathrm{CH}_{2}$ & $20 \mathrm{~min}$ & $\mathbf{4 a}, \quad 89$ \\
$\mathbf{1 b}$ & $\mathrm{H}$ & $\mathrm{CH}_{2}$ & $20 \mathrm{~min}$ & $\mathbf{4 b}, \quad 94$ \\
$\mathbf{1 d}$ & $\mathrm{Br}$ & $\mathrm{O}$ & $20 \mathrm{~min}$ & $\mathbf{4 c}, \quad 92$ \\
$\mathbf{1 e}$ & $\mathrm{Cl}$ & $\mathrm{CH}_{2}$ & $40 \mathrm{~min}$ & $\mathbf{4 e}, \quad 93$ \\
$\mathbf{1 f}$ & $\mathrm{F}$ & $\mathrm{CH}_{2}$ & $20 \mathrm{~min}$ & $\mathbf{4 f}, \quad 56^{a}+\mathbf{5 f}, \quad 31^{a}$ \\
$\mathbf{1 g}$ & $\mathrm{Me}$ & $\mathrm{CH}_{2}$ & $20 \mathrm{~min}$ & $\mathbf{4 g}, \quad 84$ \\
$\mathbf{1 h}$ & $\mathrm{CN}$ & $\mathrm{CH}_{2}$ & $20 \mathrm{~min}$ & $\mathbf{5 h}, \quad 62^{a, b}$ \\
$\mathbf{1 i}$ & $\mathrm{CF}$ & $\mathrm{O}$ & $20 \mathrm{~min}$ & $\mathbf{4 i}$, & $0^{a, c}$ \\
$\mathbf{1 j}$ & $\mathrm{NHAc}$ & $\mathrm{CH}_{2}$ & $2 \mathrm{~d}$ & $\mathbf{4 j}$, & $74^{d}$ \\
$\mathbf{1 k}$ & $\mathrm{OMe}$ & $\mathrm{O}$ & $8 \mathrm{~h}$ & $\mathbf{4 k}, \quad 92$
\end{tabular}

Conditions: Aniline $1(1.0 \mathrm{mmol}), \mathrm{H}_{2} \mathrm{O}_{2}(10 \mathrm{mmol}), \mathrm{HBr}(12 \mathrm{mmol})$ in $\mathrm{MeCN}(10 \mathrm{~mL}) ;{ }^{a}$ Additional times and equivalents produced similar results; ${ }^{b} \mathbf{4 h}$ observed but was not isolated; ${ }^{c}$ Intractable mixture of mono and non-brominated ring-fused benzimidazole; ${ }^{d} \mathrm{H}_{2} \mathrm{O}_{2}(20 \mathrm{mmol}), \mathrm{HBr}(24$ $\mathrm{mmol})$ in $\mathrm{MeCN}(10 \mathrm{~mL})$.

Figure 2. Crystal Structures of 6,8-dibromo-1,2,3,4tetrahydropyrido[1,2-a]benzimidazoles
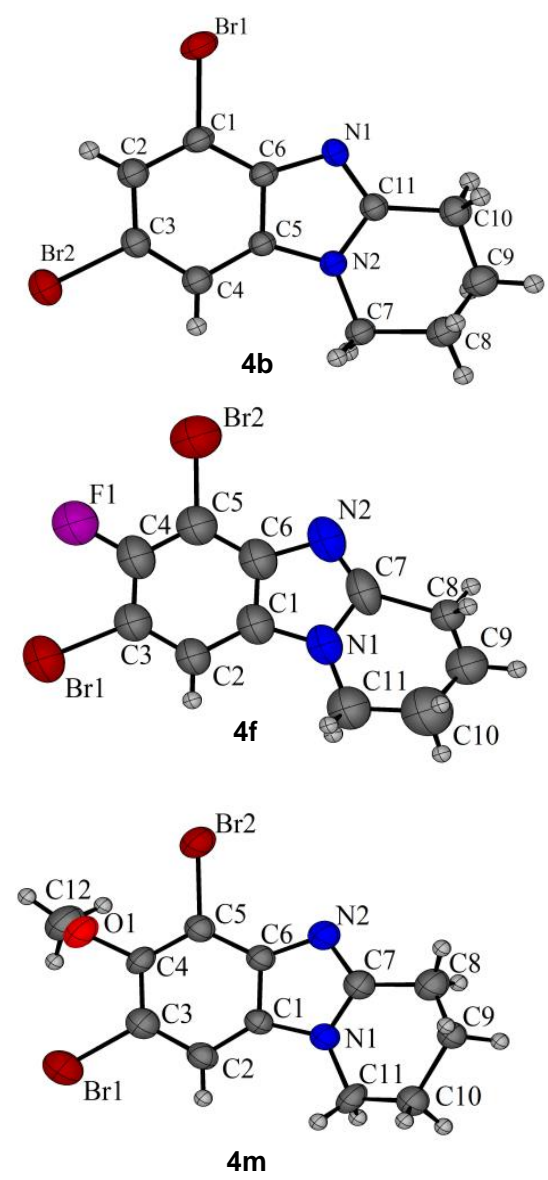

The synthesis of alternative [1,2- $a$ ] alicyclic ring-fused benzimidazoles was examined (Table 4). Selectively dichlorinated five to eight-membered $[1,2-a]$ alicyclic ring fused benzimidazoles $\mathbf{2 l - 2 0}$ were isolated in 78-93\% yield after reaction times of 20 minutes. The brominations were found to be significantly slower than the analogous chlorinations, and double the number of equivalent of $\mathrm{H}_{2} \mathrm{O}_{2}-\mathrm{HBr}$ were required to obtain the desired products. This is in agreement with literature kinetic studies for the halogenation of $p$-xylene, where $\mathrm{Br}_{2}$ was found to react more than 200 times slower than $\mathrm{Cl}_{2}{ }^{18}$ Attempts were made to reduce reac- tion times by activating bromine towards electrophilic attack by adding a quaternary ammonium salt (TBAB), ${ }^{2}$ but no effect on rate was observed. Our system is however different to the literature, ${ }^{2}$ as there is an absence of a two-phase system due to the solubility of acetonitrile in water. It is conceivable that steric factors might be also influencing the rate of electrophilic aromatic bromination, since one would have expected greater polarizability in suspected bromination species, $\mathrm{H}_{2} \mathrm{O}^{+}-\mathrm{Br}$ and $\mathrm{Br}_{2}$ compared to the chlorine analogues. ${ }^{3}$ Nevertheless selectively dibrominated pyrido-, azepino- and azocino [1,2- $a$ ] ring-fused benzimidazoles $\mathbf{4 m -}$ 4o were isolated in high yields of $70-86 \%$. Monitoring the reaction of 11 with $\mathrm{H}_{2} \mathrm{O}_{2}-\mathrm{HBr}$ using ${ }^{1} \mathrm{H}$ NMR showed after 20 minutes the formation of a mixture of monobromides; 5- and 7bromobenzimidazoles in an approximate 1:3 ratio and after 20 hours a mixture of di- and tribromides $\mathbf{4 l}$ and $\mathbf{5 l}$ remained in an approximate $2: 1$ ratio. It was thus not possible to cleanly isolate 5,7-dibromopyrrolo[1,2-a]benzimidazole $4 \mathbf{l}$, and it was decided to allow the tribromide $\mathbf{5 l}$ to be regioselectively formed in $87 \%$ yield.

Table 4. One-Pot Five to Eight-Membered [1,2-a] Ring-Fused Benzimidazole Formation with Aromatic Dihalogenation

1
1
11

Conditions: Aniline $1(1.0 \mathrm{mmol})$ in $\mathrm{MeCN}(10 \mathrm{~mL})$ with $\mathrm{H}_{2} \mathrm{O}_{2}(10 \mathrm{mmol})$ and $\mathrm{HCl}(12 \mathrm{mmol})$ for $\mathrm{X}=\mathrm{Cl}$ or with $\mathrm{H}_{2} \mathrm{O}_{2}(20 \mathrm{mmol})$ and $\mathrm{HBr}(24$ $\mathrm{mmol}$ ) for $\mathrm{X}=\mathrm{Br}$.

In conclusion we have successfully established a simple and inexpensive $\mathrm{H}_{2} \mathrm{O}_{2}$ - $\mathrm{HX}$ preparation of halogenated ring-fused benzimidazoles with 31 new compounds now reported from commercial anilines. In most cases the one-pot transformation gives regioselectively the novel dihalogenated heterocycle in high yields.

\section{ASSOCIATED CONTENT}

\section{Supporting Information}

Experimental procedures and spectroscopic data for all compounds, including X-ray crystallographic data for compounds $\mathbf{2 d}$, $\mathbf{2 i}, \mathbf{4 b}, \mathbf{4 f}$ and $\mathbf{4 m}$ is available free of charge via the Internet at http://pubs.acs.org.

\section{AUTHOR INFORMATION}

\section{Corresponding Author}

*Email: fawaz.aldabbagh@ @uigalway.ie; Tel.: +353 (0) 91 493120. Fax: +353 (0) 9149557. 


\section{Notes}

The Authors declare no competing financial interest.

\section{ACKNOWLEDGMENT}

The authors thank the College of Science, National University of Ireland Galway (NUI Galway) for a Postgraduate Scholarship for M.G. and the Irish Research Council (IRC) for a Government of Ireland Postgraduate Scholarship for M.S.

\section{REFERENCES}

1. (a) Ben-Daniel, R.; de Visser, S. P.; Shaik, S.; Neumann, R. J. Am. Chem. Soc. 2003, 125, 12116-12117; (b) Sivey, J. D.; Roberts, A. L. Environ. Sci. Technol. 2012, 46, 2141-2147.

2. Dakka, J.; Sasson, Y. J. Chem. Soc. Chem. Commun. 1987, 1421-1422.

3. Sivey, J. D.; Arey, J. S.; Tentscher, P. R.; Roberts, A. L. Environ. Sci. Technol. 2013, 47, 1330-1338.

4. (a) Barhate, N. B.; Gajare, A. S.; Wakharkar, R. D.; Bedekar, A. V. Tetrahedron Lett. 1998, 39, 6349-6350. (b) Barhate, N. B.; Gajare, A. S.; Wakharkar, R. D.; Bedekar, A. V. Tetrahedron 1999, 55, 11127-11142. (c) Bogdal, D.; Lukasiewicz, M.; Pielichowski, J. Green Chem. 2004, 6, 110-113. (d) Koini, E. N.; Avlonitis, N.; Calogeropoulou, T. Synlett 2011, 1537-1542.

5. Kuznetsov, Y. V.; Stolyarova, L. G.; Lezina, V. P.; Smirnov, L. D. Bull. Acad. Sci. USSR. Div. Chem. Sci. 1989, 38, 14941500.

6. De Rosa, M.; Canudas, N.; Arnold, D.; Yennawar, H. J. Org. Chem. 2013, 78, 7264-7267.

7. Nair, M. D.; Adams, R. J. Am. Chem. Soc. 1961, 83, 35183521.

8. Fahy, K.; Aldabbagh, F. Tetrahedron Lett. 2008, 49, 52355237.

9. Fagan, V.; Bonham, S.; McArdle, P.; Carty, M.P.; Aldabbagh, F. Eur. J. Org. Chem. 2012, 1967-1975

10. Bahrami, K.; Khodaei, M. M.; Kavianinia, I. Synthesis 2007, 547-550.

11. Martin, J.; Meth-Cohn, O.; Suschitzky, H. Tetrahedron Lett. 1973, 14, 4495-4498.

12. Carpenter, R. D.; Natarajan, A.; Lau, E. Y.; Andrei, M.; Solano, D. M.; Lightstone, F. C.; DeNardo, S. J.; Lam, K. S.; Kurth, M. J. Cancer Res. 2010, 70, 5448-5456.

13. Andrzejewska, M.; Yépez-Mulia, L.; Cedillo-Rivera, R.; Tapia, A.; Vilpo, L.; Vilpo, J.; Kazimierczuk, Z. Eur. J. Med. Chem. 2002, 37, 973-978.

14. Gobis, K.; Foks, H.; Serocki, M.; Augustynowicz-Kopeć, E.; Napiórkowska, A. Eur. J. Med. Chem. 2015, 89, 13-20.

15. Borowski, P.; Deinert, J.; Schalinski, S.; Bretner, M.; Ginalski, K.; Kulikowski, T.; Shugar, D. Eur. J. Biochem. 2003, 270, 1645-1653.

16. Šukalović, V.; Andrić, D.; Roglić, G.; Kostić-Rajačić, S.; Šoškić, V. Arch. Pharm. 2004, 337, 376-382.

17. Crystallographic data (excluding structure factors) has been deposited with the Cambridge Crystallographic Data Centre as supplementary publication CCDC 1054365 for (2d) CCDC 1054369 for (2i), CCDC 1054366 for (4b), CCDC 1054368 for (4f), and CCDC 1054367 for (4m).

18. Voudrias, E. A.; Reinhard, M. Environ. Sci. Technol. 1988, $22,1049-1056$. 